\title{
Gerald George Pashley Holden
}

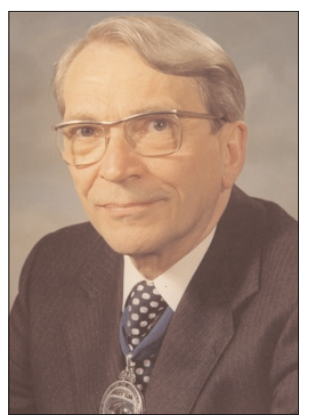

Gerry Holden attained the rare achievement of rising to the very top of the dental profession both clinically and politically as an 'ordinary' dental surgeon. From the early 1960s he helped pioneer and develop anaesthetic and sedation techniques, striving to achieve safe and effective pain and anxiety control for dental patients - and became internationally recognised for his expertise.

An elected member of the GDC for 15 years, Gerry campaigned for dental education as a specialty of medicine at a time when this was unfashionable but scientifically appropriate. He highlighted the GDC's role in protecting patients by insisting on ethical guidance that demanded justified, minimally invasive and above all safe clinical care.

In the early 1980s, the government wished the GDC to remove its ban on advertising dental services. Gerry not only warned his professional colleagues that the proposal would seriously threaten clinical freedom and judgement but, chillingly, he foresaw 'the end of NHS dentistry in this country, as we know it'. Some of his colleagues felt this was an extreme reaction. Subsequent events have proved otherwise.

Gerry was born on 18 August 1919 in Chesterfield. His father, grandfather and future wife Jean were all dental surgeons and his family has been associated with dentistry and medicine since before 1878. Educated at Chesterfield Grammar School, he started his dental training at Sheffield University in 1939. He was, at heart, something of a boffin with a keen grasp of science, particularly electronics. In his teens he became an enthusiastic radio amateur, an interest that he retained all his life.

In 1940, no longer content to serve his country by spending evenings monitoring the airwaves for enemy transmissions, he took the decision to suspend his dental studies and joined the RAF Volunteer Reserve, taking postings in the UK, India and Ceylon. On return in 1946, he resumed his dental studies at Durham University, qualifying in 1951. Following their marriage in 1952, Gerry and Jean set up practice in Chesterfield.

A turning point in Gerry's career came when he attended a training course of The Society for the Advancement of Anaesthesia in Dentistry: 'SAAD', whose motto is 'abolish pain to conquer fear'. One

\section{Gerry was a man of great far- sightedness - years ahead of his time...}

of the society's driving forces for over 40 years, Gerry became president in 1975, ending his term in 1979 by hosting the largest ever international congress on pain and anxiety control in London. He also oversaw the creation of the International Federation of Dental Anesthesiology Societies which, by 2003, had 28 countries participating.

An ardent promoter of the team approach to dentistry, Gerry espoused the principle that the dental surgeon, anaesthetist and dental surgery assistants should work as a cohesive interlinked unit. This led to his expertise in the ergonomics of surgery design; he was an internationally renowned speaker on these subjects in the UK and abroad. He also had a preoccupation with patient safety; if dental equipment did not meet his standards he would simply design something himself. In the early 1960s, recognising the importance of treating the patient in the supine position, he designed a state-ofthe-art dental couch, offering an alternative to the traditional dental chair feared by so many.

Serving on several influential committees, Gerry received the highest awards from his peers in the field of dental anaesthesia including the American Hillel Feldman Award and the Horace Wells Award from the international community. In 1977 he received the Queen's Silver Jubilee Medal for voluntarily servicing Talking Books for the Blind for over 30 years. In 1981 he was awarded the OBE for services to dentistry.

Gerry was a man of great far-sightedness - years ahead of his time, unafraid to ask 'why?' or to challenge established scientific methods. A man of strong principles and integrity, he always admitted that he had had the good fortune to spend most of his practising years in the 'Golden Age' of the NHS when a free dental service allowed him to give state-of-the-art treatment to all his patients.

A man of strong faith, throughout his life Gerry's beloved Parish Church of St Mary \&t All Saints in Chesterfield was a key anchor for him.

He is survived by two sons, Peter (a doctor), Christopher (a dental surgeon), and his daughter, Elizabeth (a solicitor).

D. Craig

\section{David J. Stanley}

The death of David Stanley occurred in Australia in a motorcar accident on 11 March 2004.

David qualified in dentistry at Birmingham University in December 1953. Following National Service in the Royal Army Corps he joined a former student colleague, Donald Mole, and Sydney Rowley in practice in Dudley, West Midlands.

David was enthusiastic and energetic in his work and increasing numbers of patients were attracted to the practice which expanded with late dental graduates from Birmingham, Alan Harper and Geoff Hiscock, joining the partnership.

David took a keen interest in intravenous sedation work and after some years left the partnership to open his own practice in Stourbridge. He emigrated to Australia in 1976 to undertake private dental practice in Northam, Western Australia. He retired from dental practice in 1992 and shortly afterwards had

\section{David was enthusiastic and energetic in his work and increasing numbers of patients were attracted to the practice...}

a heart transplant operation in Sydney. Prior to his death he was the oldest living heart transplant in Western Australia. He was very much involved with Awareness for Organ Donors discussion groups, giving talks to groups on Life After Heart Transplant. He was a member of the local hospital board, and involved with Rotary and Freemasons. He is survived by his wife Maureen, five children and seven grandchildren.

D. Mole 